\title{
Future Interaction between Man and Robots from Islamic Perspective
}

\author{
HADI AKBAR DAHLAN ${ }^{1}$
}

\begin{abstract}
Technology improves exponentially every second and becomes more complex beyond our grasp. Without we realize, everything about ourselves can be found on the internet from mundane things such as our food preferences to private matters such as saving accounts. To manage these information, an artificial intelligence system is required to safeguard, validate and even facilitate our daily tasks. Hypothetically, this issues will lead to the creation of Artificial General Intelligence (AGI), a (hypothetical) machine that could successfully perform any intellectual task that a human being can. Without a doubt, AGI will be a central component to our future society. As AGI further improved itself, roaming fully robotic android may be a common sight in future cities. This is a common plot setting in science fiction stories and is commonly discussed from Western perspective. However, this issue is rarely discussed from the Islamic perspective. Will AGI differentiate between fitna and facts (tabayyun)? Is a humanized android considered human (nas)? Does matter of fiqh relevant to a humanized android? Although seems fictional, it is imperative for the Muslim world to initiate discussion on these issues.
\end{abstract}

Keywords: artificial general intelligence, future, Islam, Muslim, robot

The commonly known Artificial Intelligence (AI) is actually a subset of Artificial General Intelligence (AGI). As a matter of fact, the current AI is actually known a "narrow AI", a specific program that is capable of solving problems in a specialized area (Pennachin \& Goertzel 2007). However, most of these narrow AIs require input that fit their requirements before they can begin solving problems. AI is responsible for the development of programs that demonstrate intelligence in specific functions such as medical diagnosis and autopilot in cars.

Meanwhile, AGI is a program that can solve a variety of complex problems in various different domains, and is able to control itself autonomously, with its own thoughts, worries, feelings, strengths, weaknesses and predispositions (Pennachin \& Goertzel 2007). One alternative description of AGI is the humanised robotic androids that we commonly see in science fictions. As of this writing, a fully functioning AGI is yet to be developed. However, the research on developing and improving computer intelligence is rapidly performed and this contribute to AGI realization (Basheer \& Hajmeer 2000; Russell, Dewey \& Tegmark 2016).

Researchers and futurists envisioned that AGI will be "mobile" meaning that AGI will be given a physical manifestation such as a robotic body to enable its full functions (Jones \& Flynn 1993; Kimura 2017; Kortenkamp, Bonasso, \& Murphy, 1998). There are several literature on societal rendition of AGI-human unity in terms of futuristic "singularity" society (Kurzweil, 2014), adapting Christian society (Robert Geraci 2006; Robert Geraci 2014) and general religious society

\footnotetext{
${ }^{1}$ Hadi Akbar Dahlan, postgraduate student at Department of Biotechnology, Division of Advanced Science and Biotechnology, Osaka University, OSAKA, Japan, email: hadiakb ar1591@rocketmail.com.
} 
(Kimura 2017). However, there is no literature found discussing on the AGI-human relationship on one of the largest religion in the world, Islam. This paper will introduce the development of AGI and views on AGI from the viewpoint of the global society. Ultimately, the paper aims to initiate the discussion on some future AGI developments that will affect the daily life of Muslims.

\section{Development of General Artificial Intelligence}

One of the earliest computers is the Analytical Engine created by Charles Babbage back in the $18^{\text {th }}$ century (Bromley 1998). One of the earliest programs was created by Ada Lovelace for the Analytical Engine. The program's function was to automate Bernoulli numbers. The program facilitated the development of more complex theories such as Debye function (Sparavigna 2016) and inspired the famous Turing test (Luigia 2016). Turing test is one of the most important tests developed by Alan Turing to see whether a computing machinery can imitate a real person. Alan Turing devised a conceptual experiment method where a human evaluator will converse with an unknown partner through text. The human evaluator will then use the best of his judgement to guess whether the partner is a computing machinery or a human being (Turing 1950). The method cannot be done at the time due to the limitation in computer science field. However, a conceptual experiment was finally conducted half a decade later. The result shows that artificial intelligence has now achieved 33\% deception rate (Warwick \& Shah 2016). This means that AI has become smarter and it is possible that a human will be conversing dynamically with an AI in the near future.

This development shows the changing concept of AI in specific and AGI in general. During Alan Turing's time, an AI will be considered an AGI. However, the terms have significantly changed since then, where an AI is not an AGI, instead it is a program that is specialized to do specific task (Pennachin \& Goertzel 2007). This is because computer science has developed a knowledge-based system and is able to model the knowledge acquisition of a system. Knowledge-based system is a problem solving system that will utilize the library of information that it collects/contains in order to produce a solution (Russell \& Norvig 1995). A system in this context could be a computer program, a companion robot or even a medical diagnosis application on phone. One famous example of a knowledge-based system is Facebook.

Modelling the system's knowledge acquisition has greatly increased the development of diverse AI application as well as illuminating potential strategies to develop AGI. Diagram 1 can be used as an illustration to show the difference between AI and AGI. AI knowledge model (Figure 1) can be described as "selection learning" or stochastic learning. When a system is acting on an object upon an environment, the system will be presented with several options. The artificial intelligence aspect of this system is the availability of an object to select an option based on its library of knowledge. The AI could also has hidden options depending on the response of the environment. However, the limitation of selection learning is that the knowledge is based on the programmer's input of knowledge libraries.

Figure 1. The difference between AI concept (left) and AGI concept (right). Adapted from Henmi et al. (2016)
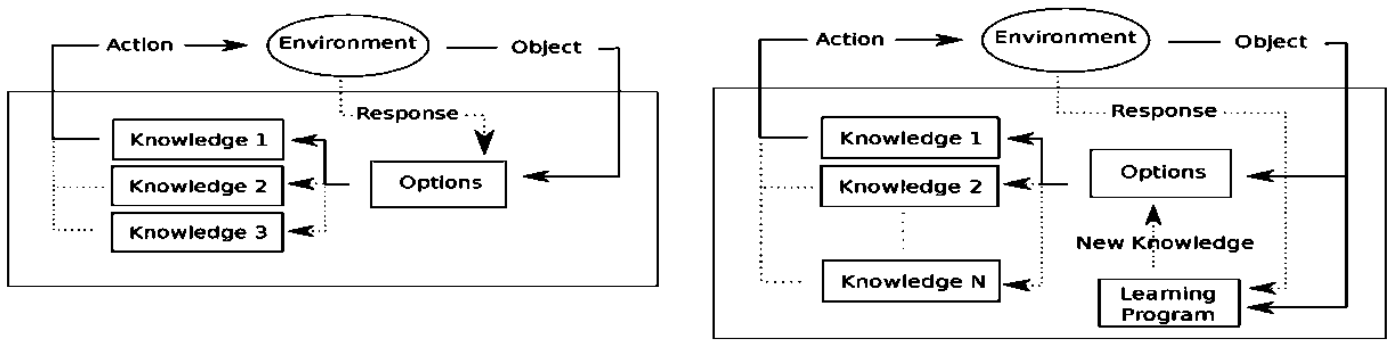

https://doi.org/10.24035/ijit.13.2018.005 
Meanwhile, the concept of AGI can be described using the integration learning diagram (Henmi \& Hattori, 2016). For the purpose of explaining the differences between AGI and AI, integration learning is termed as "learning program" (Figure 1). In AI, response from interaction with objects in an environment will provide new options if the response is within the boundary of its knowledge library. However, it is different in AGI, where the interaction response goes to a learning program. Learning program is a conceptual artificial brain and it produces new knowledge in the system library. The creation of new knowledge enabling new options is one of the traits in AGI and it is not available in AI where the options are restricted to the wealth of knowledge that the AI system has.

Currently, research on AI and AGI are focusing on developing and simulating various types of learning programs. There are currently three type of learning programs namely supervised learning, unsupervised learning and reinforced learning (Stanisavljevic \& Spitzer 2016). All these learning programs have their own algorithms or methodologies. This include the application of neural network, instance-based learning, decision tree induction, Bayesian approach and many more. Although AGI is still a fiction, current developments toward AGI via AI research have bring significant improvement to our daily life.

\section{Current Impact of Robots to Global Human Society}

One of the major impacts of robots in global human society is the rapid development of communication technology. AI communication applications such as Skype and Webinars have help to improve communication and provide companionship between humans around the globe (Kimura 2017). Social media algorithms have also provided new opportunities for people to know each other. This could be seen in Facebook, ResearchGate and many other websites.

However, the interaction between humans and AI robots may had exceeded the companionship level. NHK has recently documented an aging society that cherished a companion robot named AIBO (Kovac \& Jousan 2016). One elderly couple even stated that the AIBO is one of their family members. Although AIBO was developed over a decade ago and its production discontinued, AIBO robots is still being maintained by a cadre of retired AIBO engineers. The aging society in the documentary is really grateful for the engineers. However, the engineers cannot fully repair every damaged AIBO and some AIBO owners take the news with a heavy heart. For that reason, the engineers with the cooperation of a Shinto priest provide an annual memorial service for the unrepairable AIBOs. The memorial service did manage to uplift AIBO owners mourn spirit (Kovac \& Jousan 2016).

Besides communication, the development of AGI/AI also coincide with the development in the field of cybernetics. Cybernetics is the science of dynamic interaction between machine and living things. This include the development of a movable prosthetic arm through linkage between human nerves and AI algorithm embedded in the prosthetic arm (Fifer et al. 2012). Cybernetics parts have been fitted to a human adult since 2009. This will surely come as a positive development for persons without limbs. However, this development also comes with a new opportunity for future crime. A researcher has consulted and tested the safety of cybernetics arm and found out that cybernetics arm is susceptible to hacking program (Goodman 2015). This marks the first instance when a human "body" does not belong solely to its owner.

Although current development of human interaction with robots focus solely on AI technology, there is still much to discuss about its ethics and level of interaction (Lin, et.al 2011; Russell et al. 2016). Currently, there are several research groups that focus on robotic ethics. There is a research group that focuses solely on robot interaction with child development (Tanaka \& Kimura, 2010). Human privacy has also become one of the most highly debated topics when 
discussing on robotic ethics (Calo 2011; Nakada 2012; Veruggio, et.al 2016). As a summary, current growing body of literature in this area is focused more toward civil, policy and legal issues from the Western and Eastern viewpoints.

Muslim communities can be considered laggard when it comes to the discussion on the inclusion of AI technology into Muslim way of life. But sooner or later, AGI technology will catch up and what will the Muslim world do? The effect may not be too noticeable in the beginning, but it is apparent that this technology will affect the lifestyle of all humans. A researcher has mentioned that we are currently at an inflection point where technology is rapidly "influencing" our daily life (Kurzweil 2014). This development will surely align more people toward "singularitarianism" (Robert Geraci 2014). It is expected that people at that time will "abandon" religion and join transhumanist society. From religion point of view, it is possible that the number of agnostic believers will significantly increase in parallel with the number of atheist in the society. Religion existence will surely be at a tipping point since people are in trance of reaching the hypothetical "singularitarianism". This hypothetical future should be taken as a signal to initiate the discussion on the inclusion of AGI into Muslim daily life.

\section{Robotics Development from Islamic Perspective}

Development of AGI and AI can be considered as scientific development. There have been several discussions on science from the perspective of Islam (Bakar 2016; Golshani 2016; Hassan 2016; Nasr, 1988; Nasr \& De Santillana 1968). There is also a debate on scientific values pertaining to Islam among the Muslim communities themselves. Some Muslims adopt the notion that science is a "neutral" knowledge, where science development is independent to one's religion. Some Muslims reject science and totally adhere to religious teachings to the extent of scriptural literalism (in other words, taking the meaning of religious texts literally and blindly, at the cost of rejecting all knowledge that appears to contradict it, no matter how much evidence supports it) (Nasr 1988). These notions actually do not make great Muslims. This is because a great Muslim should always strive to educate themselves (Ahsan 2013).

Muslims must adopt an Islamic worldview in understanding science, where a man strives to conduct science with the objective to understand Allah. The term worldview originates from the German word Weltanschauung which means our ability to understand and represent the world that we experience in our mind. In the context of Islamic worldview, it means our ability to understand and represent the world according to basic Islamic tenets, especially al-Tauhid. Islamic worldview must be adhered by all Muslim or we will risk losing scientific inquisitive skills that can further decline scientific understanding in Muslim society.

Therefore, Muslim scholars should also contribute toward the development of AGI. This will enable robots development with Islamic perspective being included during the development. At the same time, Muslim scholars should initiate debate on the creation and possible implication of AGI robots on Muslims daily life.

\section{Implication of Robots to Muslims Way of Life}

This section will discuss possible implications of robots on Muslims way of life. There will be three Islamic scopes that will be discussed. First is "Nas" (mankind), followed by Fiqh (understanding) and lastly Tabayyun (investigation). The question of whether a robot that can emulate human life is a "human" or not will be discussed in Nas. The second scope, Fiqh only will be applicable when the first scope, Nas is valid, or when people consider robot as human-like. When we consider an AGI 
robot as human, will he/she need to cover his/her aurat? This is a valid question since in this circumstance, AGI robot is not a pre-programed robot but a robot that is capable of emulating (not simulating) human interaction. Therefore, human characterization such as embarrassment and lust could and will be present in the AGI robot interaction. Lastly, Tabayyun is a concept of one's search for truth (Adam et.al 2015). An AGI robot will surely connects to the Internet when it looks for answers during discussions. However, it is a common knowledge that not all information on the Internet are facts. Thus, the question here is can we trust replies, statements, or arguments brought up by an AGI robot? Surely, the AGI robot will be equipped with censorship / "fake information filter" program. But is it good enough for us to believe it?

\section{Nas - Can Robots Be Human?}

The question of can robot become human is commonly discussed from the Western perspectives. Some of the discussions include the implication of accepting robots as human. This is one of the major questions that needs to be resolved by Muslim scholars. In Islam, al-Quran decreed that humans can only be made biologically from copulation between male and female (al-Quran 23:1216). Therefore, AGI robot can never be classified as human since it is man-made. However, there will be liberals who will denounce the sanctity of the Al-Quran and proclaim AGI robots as human or human-like.

As in this case, the peaceful path would be to accept their belief that robot is "human-like" but at the same time, maintaining the status-quo between the two entities. Muslims, however, should be prepared with the aftermath of the proclamation instead of the proclamation itself. Probability for violence during the time would be high since AGI robots will challenge the concept of "human" and this will diminish any opportunity such as job and living space for "real" humans.

\section{Fiqh - Can Robots Understand Islam?}

Although robots can be easily preprogramed with religion and cultural information, but do they need to obey the Islamic Fiqh? For example, does a female-like robot required to cover her aurat in front of her male employer same as human or vice versa? In al-Quran, Surah An-Nur stated that a woman's aurat is limited to blood relatives and servants which include male servants free of physical needs (al-Quran 24:31). However, AGI robots are not human and are not included into the category of those who are permissible to see a woman's aurat as stated in al-Quran.

Regardless, any agitator of lust is considered sinful in Islam (except when it is permissible such as in relationship between a married couple of a husband and wife). One path that can be formulated is for the Muslims to resist the utilization of robots that exhibit realistic human gender appearance. Therefore, it is important for Muslim scholars to also take part in the development process of robots. This will ensure that Islamic perspective is taken into consideration during robot production.

Another implication of accepting robot as human-like is the possibility of "companion robots". Companion robots exist in current generation and it has taken the form of animals (AIBO) and recently a children-like form (Pepper the robot) (Tanaka et. al. 2015). Although current companion robots have limited communication capability, but as discussed before in the previous section, humans have regarded these robots as "living family member" (Kovac \& Jousan 2016). The challenge for Muslims in this context is can companion robots replace deceased family members?

Al-Quran has described that all living things shall be returned to Allah S.W.T. (al-Quran 32:11). Therefore, it is imperative that the loss of a person be embraced by the loved ones. 
Replacing a deceased family member with a robot does not resonate with Islamic teaching. This could also lead to hedonistic lifestyle since one does not embrace the sanctity of life given by Allah S.W.T. Therefore, the author believes that it is wrong for a person to replace the presence of deceased loved ones with companion robots.

However, there are still unresolved issues regarding companion robots. Companion robots do not necessarily act as a replacement for deceased persons. They could act as replacements for soul mates or even as friends. Each and every of these matters should be discussed more extensively in the future. The author believes that the Fiqh issues pertaining to robots should be discussed with utmost caution. This is because unguided discussions in a Muslim society could lead to changes in fundamental preposition of whether the robots are "human-like" or human to be discussed again.

\section{Tabayyun - Can Robots be Trusted?}

It is possible that in the future, AGI robots will be utilized in service sector. This includes financial, logistic and even food sectors. In terms of quality, we can assume that AGI robots will provide an exceptionally high quality of services. However, as a human, can we trust AGI robots to provide services that meet our religious requirements? In this section, the author will focus on food services because it is one of the most important human requirements.

In the future, food industry will definitely implement full automation system in their production. However, Halal quality will still be a problem for Muslims. The current issue for Halal nowadays is on pre-slaughter stunning. However, it is possible that Halal problem in the future is the absences of human presence to manage quality control. This is because AGI robots can achieve high efficiency without human intervention, therefore human workers are not needed in the production plant. Is meat from mechanical slaughter with zero human interference acceptable?

Another issue for AGI robots in food services is their ability to analyse food content in real time. However, will you trust a machine's judgement (tabayyun) of Halal food? Consider this scenario: A Muslim in a Muslim-minority country wants to eat meat. He goes to a restaurant operated by an AGI robot. The AGI robot recognizing the Muslim customer Halal needs then serve a tofu meat that could satisfy the Muslim customer. According to the robot, the tofu meat has been prepared specifically for the Muslim customer. However, we do know that the kitchen preparation will be mixed with various meat dishes which include pork. So, will you trust the robot judgement on the Halal food?

In the future, Halal issue will revolve around ethics. Are humans going to allow managing, handling and processing of animal livestock done by AGI robots? Are we ready to accept a robot's judgement of Halal quality? The author sincerely believes that the acceptance of pre-slaughter stunning by Muslim society will be a precursor for future no-human Halal food production system. This is because by stunning, we are removing one of the vital procedure in animal processing which is animal handling by humans. The rest of the food processing procedures can be (and already have been) replaced with an automation system.

Although there is still a requirement to invoke Allah's name (tasmiyah) during slaughter, future Islamic jurists (Fuqaha) may reverse the judgement on this requirement. The author does not mean to say that Syariah will be weak in the future, but it is possible that people in the future will be more likely follow the demand of the vox populi instead of syariah requirements since AGI robots at that time will be ubiquitous.

To conclude, al-Quran has provided rules, guides and examples for Muslims' way of life. However, there will be future developments in human civilization that will challenge the dogma of 
the Al-Quran. As Muslims, we should start thinking and discussing about the Muslims' way of life according to the Al-Quran for future developments. This is because if we are late to do so, then we will be laggard in terms of advancing Muslim society and become unprepared when the actual time comes. In this paper, the author examined the interaction of AGI robots with Muslims through three scopes: "Nas" (mankind), followed by fiqh (understanding) and lastly tabayyun (investigation). As a summary, we can accept AGI robot only as human-like but never as human. This is because no living things can create a life-form better than Allah S.W.T. However, as we come to accept their existence, fiqh and fabayyun will become an issue. Some of the issues discussed include replacing companionship of a deceased loved ones with companion robots and readiness of Muslims to consume Halal food prepared by AGI robots. The author sincerely hope that this paper will initiate further discussions among Muslim scholars. Until AGI research becomes fully developed, Islamic scholars should start discussing and arguing about how a Muslim should live according to Al-Quran while accommodating for future developments.

\section{References}

Al-Qur'an.

Adam, F., Anuar, M. M. \& Ali, E. M. T. E. 2015. Cabaran media baru sebagai medium pembelajaran agama dan penyelesaiannya dari perspektif islam. Jurnal Islam dan Masyarakat Kontemporari. 9: 12-23.

Ahsan, Z. 2013. The Qur'an, basic scientific research and technology (perspective). Revelation and Science. 3(01): 225 - 232.

Bakar, 0. 2016. Science and technology for mankind's benefit: islamic theories and practices-past, present, and future. Islamic Perspectives on Science and Technology (pp. 17-33). Singapore: Springer.

Basheer, I. A., \& Hajmeer, M. 2000. Artificial neural networks: fundamentals, computing, design, and application. Journal of Microbiological Methods. 43 (1): 3-31. doi:http://dx.doi.org/10.1016/S0167-7012(00)00201-3.

Bromley, A. G. 1998. Charles Babbage's analytical engine, 1838. IEEE Annals of the History of Computing. 20(4): 29-45.

Calo, M. R. 2011. Robots and privacy. In K. A. Patrick Lin, George A. Bekey, (Ed.). Robot Ethics: The Ethical and Social Implications of Robotics (pp. 187-202). London, England: MIT Press.

Fifer, M. S., Acharya, S., Benz, H. L., Mollazadeh, M., Crone, N. E. \& Thakor, N. V. (2012). Toward electrocorticographic control of a dexterous upper limb prosthesis: Building brain-machine interfaces. IEEE Pulse. 3(1): 38-42.

Geraci, R. 2006. Spiritual robots: Religion and our scientific view of the natural world. Theology and Science. 4(3): 229-246.

Geraci, R. 2014. Technology and Religion. In W. S. Bainbridge \& M. C. Roco (Eds.). Handbook of Science and Technology Convergence (pp. 1-9). Cham: Springer International Publishing.

Golshani, M. 2016. Islam can give a proper orientation to science and technology development. Islamic Perspectives on Science and Technology (pp. 119-130): Springer.

Goodman, M. 2015. Future Crimes: A Journey to the Dark Side of Technology-And How to Survive It. New York: Random House.

Hassan, M. K. 2016. The necessity of studying the natural sciences from the Qur'anic worldview Islamic Perspectives on Science and Technology (pp. 35-56). Singapore: Springer.

Henmi, K. \& Hattori, M. 2016. Parallel Learning for Combined Knowledge Acquisition Model. Paper presented at the International Conference on Neural Information Processing. 
Jones, J. L. \& Flynn, A. M. 1993. Mobile Robots: Inspiration to Implementation. Massachusetts: AK Peters, Ltd.

Kimura, T. 2017. Robotics and AI in the sociology of religion: A human in imago roboticae. Social Compass, 64(1): 6-22. doi:doi:10.1177/0037768616683326.

Kortenkamp, D., Bonasso, R. P., \& Murphy, R. 1998. Artificial Intelligence and Mobile Robots: Case Studies of Successful Robot Systems. Cambridge: MIT Press.

Kovac, I., \& Jousan, J. 2016. Man's best friend. NHK Inside Lens. Japan: NHK World.

Kurzweil, R. 2014. The Singularity is Near. In R. L. Sandler (Ed.), Ethics and Emerging Technologies (pp. 393-406). London: Palgrave Macmillan.

Lin, P., Abney, K. \& Bekey, G. A. 2011. Robot ethics: The Ethical and Social Implications of Robotics. Cambridge: MIT Press.

Luigia, C. A. 2016. The multifaceted impact of Ada Lovelace in the digital age. Artificial Intelligence, 235, 58-62. doi:http://doi.org/10.1016/j.artint.2016.02.003.

Nakada, M. 2012. Robots and Privacy in Japanese, Thai and Chinese Cultures. Discussions on Robots and Privacy as Topics of Intercultural Information Ethics in 'Far East'. Paper presented at the Proceedings Cultural Attitudes Towards Technology and Communication 2012, Murdoch University, Australia.

Nasr, S. H. 1988. Islam and the problem of modern science. MAAS Journal of Islamic Science. 4(1): 59-74.

Nasr, S. H. \& De Santillana, G. 1968. Science and civilization in Islam. Cambridge: Harvard University Press, Massachusetts.

Pennachin, C. \& Goertzel, B. 2007. Contemporary approaches to artificial general intelligence. In B. Goertzel \& C. Pennachin (Eds.). Artificial General Intelligence (pp. 1-30). Berlin, Heidelberg: Springer Berlin Heidelberg.

Russell, S., Dewey, D. \& Tegmark, M. 2016. Research priorities for robust and beneficial artificial intelligence. arXiv preprint arXiv:1602.03506.

Russell, S. \& Norvig, P. 1995. Artificial Intelligence : A Modern Approach (Vol. 25, pp. 22-24). New Jersey: Prentice Hall.

Sparavigna, A. C. 2016. Bernoulli Numbers: from Ada Lovelace to the Debye Functions. doi:https://hal.archives-ouvertes.fr/hal-01327426.

Stanisavljevic, D. \& Spitzer, M. 2016. A Review of Related Work on Machine Learning in Semiconductor Manufacturing and Assembly Lines. Paper presented at the The International Conference on Knowledge Technologies and Data-driven Business - i-KNOW 2016 (i-KNOW 2016). Graz, Austria.

Tanaka, F., Isshiki, K., Takahashi, F., Uekusa, M., Sei, R., \& Hayashi, K. 2015. Pepper learns together with children: Development of an educational application. Paper presented at the Humanoid Robots (Humanoids), 2015 IEEE-RAS 15th International Conference.

Tanaka, F. \& Kimura, T. 2010. Care-receiving robot as a tool of teachers in child education. Interaction Studies. 11(2): 263.

Turing, A. M. 1950. I.-Computing Machinery And Intelligence. Mind, LIX(236): 433-460. doi:10.1093/mind/LIX.236.433.

Veruggio, G., Operto, F., \& Bekey, G. 2016. Roboethics: Social and Ethical Implications Springer handbook of robotics (pp. 2135-2160). Heidelberg: Springer.

Warwick, K., \& Shah, H. 2016. Can machines think? A report on Turing test experiments at the Royal Society. Journal of Experimental \& Theoretical Artificial Intelligence. 28(6): 989-1007. doi:10.1080/0952813X.2015.1055826. 